\section{Flow of Visco-Elastic Materials in Capillaries}

IN a previous communication ${ }^{1}$ an error in pressure measurement was pointed out, which might lead to spurious results in measuring the viscosity of certain anomalous liquids. Reference was also made to viscosity determinations recently carried out on rubber solutions and the like, using a viscometer in which the true pressure-drop along the capillary was measured directly. The measurements indicated the existence of an end effect, the ratio of the length, $L$, to the diameter, $D$, of the capillary, being a significant factor. A typical family of flow curves for one rubber solution, plotted in the conventional manner, is indicated in Fig. 1. These clearly show that if the $L / D$ ratio is sufficiently large, the curves approximate closely to a line which is independent of capillary bore. Smaller $L / D$ ratios give curves diverging from this, indicating a higher apparent viscosity, the divergence increasing as $L / D$ decreases. These curves emphasize the importance of using long tubes, particularly at high stresses, if the results are to be assumed to apply to an equilibrium condition.

This effect, in which long capillaries indicate lower apparent viscosities than short ones, has already been observed for rubber solutions and other visco-elastic materials ${ }^{2,3}$. In order to explain this, we may suppose the material on entering the tube to be 'stretched', or elastically deformed, until equilibrium is reached for the particular shearing stress applied, the material then flowing through the remainder of the tube in this state. For very long tubes, this 'elastic end effect' would tend to become negligible in comparison with the overall length, and flow curves would then give a true, or nearly true, representation of the behaviour of the material under the particular con. ditions. As the tube length decreases, the end effect becomes large in proportion to the total length, and we should expect a progressive departure from the limiting curve, such as that illustrated in Fig. 1. We should also expect this end effect to increase in magnitude with increasing stress and this would, in turn, accentuate the difference in the flow curves between capillaries of differing $L / D$ ratio. Fig. 1 clearly shows this effect with increasing stress, and further, this end 'correction' deduced from the flow curves and expressed in tube diameters is actually proportional to shearing stress. A similar effect ought to occur if the concentration were increased, and this is, in fact, found experimentally. Curves similar to those shown have also been obtained with mineral

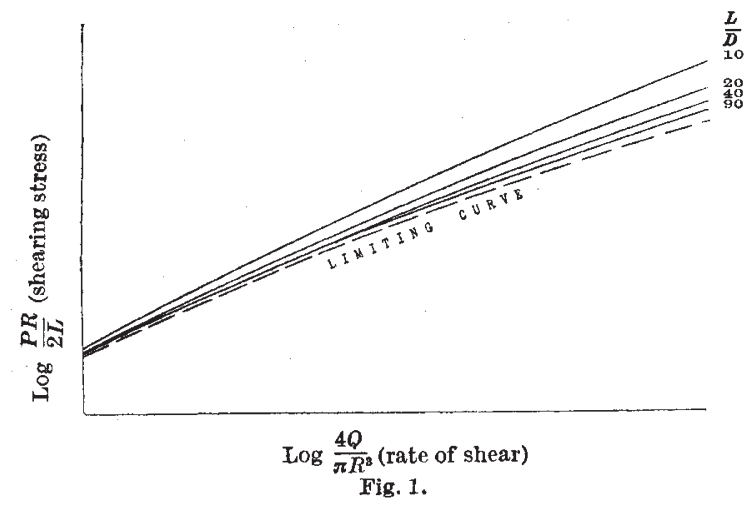

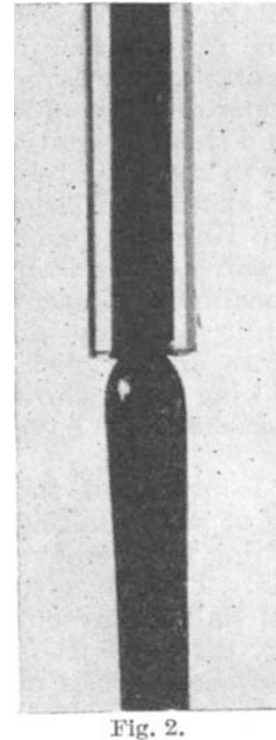

oils containing metallic soaps.

When the liquid emerges from the capillary it is still elastically deformed and will consequently tend to return to its former 'unstretched' condition. This results in a swelling of the emergent column of liquid which is easily observed, as Fig. 2 shows ${ }^{4}$. It is evident that elastic recovery commences at the actual capillary end. As with the 'elastic end effect', it is to be expected that this swelling will increase both with increasing stress and increasing concentration, and this is found to be so for the materials in question. Here again we find that elastic recovery is propor. tional to stress.

In other words, the 'elastic end effect' which results in a difference in the flow curves, and the swelling of the emergent column of liquid, are related, and either should give a measure of the elastic property of the material.

\section{A. C. Merrington.}

6 Redford Road,

Horsham,

Sussex.

Nov, 2.

${ }^{1}$ Merrington, A. C., Nature, 152, 214 (1943)

2 Peek and Ericson, J. Rheol., 2, 351 (1931)

3 Scott Blair, G. W., "An Introduction to Industrial Rheology" (London: Churchill Itd., 1938).

- Barus phenomenon, Amer. J. Sci., (3), 45, 87 (1893).

\section{High-Angle Edge Flaking of Flint}

THe recent communications on this subject by Mr. J. Reid Moir ${ }^{1}$ and Mr. Alfred S. Barnes show that the old battle over the artificial or natural origin of eoliths is on again. Space does not permit quotation of the opinions on both sides of the original argument starting in about 1912, but it seems to me that, among other things, Moir has proved two important points: (1) that it is possible for modern man to take high-angle flakes off flint cores; and (2) that among other criteria of intentional work on primitive stone artefacts one of the most important is that the edge flakes are taken off in an adjacent series, thus giving an edge of desired shape ${ }^{3}$.

As Barnes points out, use was sometimes made of steep flaking in palæolithic work; but he seems to think that primitive man was not likely to use this type of flaking to any great extent. From this he assumes that the frequency of its occurrence on supposed implements can be used as a criterion of their intentional or natural origin. This process of reasoning leads to the danger of arguing in a circle. In any event his analysis ${ }^{4}$ of the use of steep flaking in certain palæolithic industries is misleading, as he omits the Aurignacian, in which special use was made of steep flaking, and the Magdalenian, where the removal of flakes from cores can only be done by steep flaking relative to the core.

Now if Moir's criterion is applied to the flaked flints which are claimed by Barnes to have been done by some natural means, especially those from Central 